\title{
Retrospective analysis of stillbirth at a tertiary care hospital
}

\author{
Sarika Gautam*, Vandana Rani, Monika Dalal
}

Department of Obstetrics and Gynecology, Pt. B D Sharma PGIMS, Rohtak, Haryana, India

Received: 16 July 2018

Accepted: 28 August 2018

\section{*Correspondence:}

Dr. Sarika Gautam,

E-mail: sarika.gautam07@gmail.com

Copyright: (c) the author(s), publisher and licensee Medip Academy. This is an open-access article distributed under the terms of the Creative Commons Attribution Non-Commercial License, which permits unrestricted non-commercial use, distribution, and reproduction in any medium, provided the original work is properly cited.

\section{ABSTRACT}

Background: Stillbirth is a matter of concern for mother and family as it leads to mental trauma and requires a supportive counselling about the cause of death, management of current pregnancy and future of next pregnancy.

Methods: Present retrospective observational study was conducted at a tertiary care hospital over a period of 3 years which include 1765 females who had foetal death. Pregnancy of $\geq 28$ week or fetal weight $\geq 1000$ gram were taken as inclusion criteria.

Results: Total number of births in above said period were 32085 and number of total stillbirth reported were 1765 that is $5.5 \%$ of total birth. Maximum cases had their first pregnancy (45.3\%) and of were of 20 to 25 -year age group $(61.02 \%)$, and most of them were illiterate $(63.96 \%)$ and belong to low socioeconomic status (95.8\%). The causes for stillbirth were divided into four groups - medical, obstetrical, placental and unexplained causes which were $6.96 \%$, $31.38 \%, 14.10 \%$, and $47.53 \%$ respectively. Management of stillbirth was done as per standard protocol for the department and $90.9 \%$ cases had vaginal deliveries, $8.8 \%$ cases had caesarean section, and $0.16 \%$ had operative vaginal delivery.

Conclusions: Stillbirth is a hidden component of new born health status which is often neglected when we talk about perinatal mortality and infant mortality. Majority of case had hypertensive disorders of pregnancy followed by antepartum haemorrhage, infection and congenital malformations.

Keywords: Antepartum haemorrhage, Hypertensive disorder of pregnancy, Infection, Stillbirth

\section{INTRODUCTION}

Stillbirth is a devastating situation for a mother as well as for the family. It leads to psychological impact on the family specially the couple in terms of future pregnancy outcome and existing pregnancy treatment and management. An obstetrician is also in dilemma to break this bad news and counselling for these woeful couple. The definition recommended for international reference of stillbirth is "a baby born without signs of life at or beyond 28 weeks." The American College of Obstetricians and Gynaecologists (ACOG) defines stillbirth as delivery of fetus which shows no signs of life e.g. absence of breathing, heart beats, pulsations in umbilical cord are absent, no voluntary movement of muscle. The suggested requirement is to report fetal deaths at 20 weeks or greater of gestation (if the gestational age is known) or a weight greater than or equal to $350 \mathrm{~g}$ if the gestational age is not known. The cut-off of $350 \mathrm{~g}$ is the 50th percentile for weight at 20 weeks gestation. ${ }^{2}$ The United Kingdom defines stillbirth as fetal death at 24 or more completed weeks of gestation. ${ }^{3}$ The incidence of stillbirth also varies from developed countries to developing countries, higher rate seen in developing countries than developed countries simultaneously the causes are also varied from developing to developed countries. The global estimate is $18.4 / 1000$ live birth and it varies from $2 / 1000$ to $40 / 1000$ 
live birth from developing to developed countries. ${ }^{4,5}$ The multiple definition of stillbirth led to confusion and quite uncertainty in their registry system and exact load of burden is still unclear.

\section{METHODS}

This study is retrospective observational study of case files with mention of stillborn fetus. The study includes three-year retrospective data from January'2015 to December'2016 at Dept. of Obstetrics and Gynaecology, Pt. B D Sharma Post Graduate Institute of Medical Sciences, Rohtak, Haryana.

The aims and objective of the study were to know the incidence of stillbirth occurred or reported at institute and to analyses the causes of stillbirth.

The inclusion criteria were taken all those cases who reported at study site with the report of stillbirth or stillbirth occurred during the course of hospital stay. It includes all those case files which had diagnosis of $\geq 28$ weeks or birth weight $\geq 1000$ grams.

The data were analyzed for their booking status, demographic profile in terms of their age, parity, residential area, and literacy status, their economic status and number of members in the family.

Data was analyzed for their previous or existing medical history, obstetrical history in terms of their gestational age at still birth, history of previous caesarean section, previous fetal death, and previous history of abortions. The causes of stillbirth classified into medical causes, obstetrical causes, placental causes and unidentified causes.

Unidentified cases were labelled "Unidentified" when the cause of stillbirth could not be traced.

Management was done as per standard protocol for the department and $90.9 \%$ cases had vaginal delivery while $8.8 \%$ cases had caesarean section and $0.16 \%$ cases had operative vaginal delivery.

\section{RESULTS}

Total number of deliveries occurred during the study period were 32085 out of which 1765 cases were identified as stillbirth as per inclusion criteria. On calculation the rate of stillbirth for the institute it was 55 per 1000 live birth. Demographic details are depicted in Table 1.

Most of the females were primi gravida (45.3\%) of age group of 20 to 25 years $(61.02 \%)$, belong to low socioeconomic $(67.9 \%)$ status.

Most of the females were un-booked cases $(84.98 \%)$ and belong to rural area $(71.0 \%)$ and were illiterate
(63.96.0\%) and of large family that is family more than 5 members $(67.9 \%)$. Majority were referred cases $(67.98 \%)$ while $(24.87 \%)$ cases reported directly in OBG casualty and $(7.13 \%)$ cases were indoor hen they had still birth.

Table 1: Demographic details.

\begin{tabular}{|lll|}
\hline Demography & Number of patients & $\%$ \\
\hline Age (Years) & & \\
\hline$<20$ & 37 & 21.0 \\
\hline $20-25$ & 1077 & 61.02 \\
\hline $26-30$ & 501 & 28.39 \\
\hline $31-35$ & 120 & 6.80 \\
\hline$>35$ & 30 & 1.70 \\
\hline Parity & & \\
\hline G1 & 800 & 45.3 \\
\hline G2 & 416 & 23.5 \\
\hline G3 & 370 & 20.4 \\
\hline G4 & 153 & 8.6 \\
\hline$>$ G4 & 120 & 6.75 \\
\hline Residential area & & \\
\hline Rural & 1253 & 71.0 \\
\hline Urban & 512 & 29.0 \\
\hline Booking status & & 84.98 \\
\hline Unbooked & 1500 & 15.01 \\
\hline Booked & 265 & \\
\hline Literacy status & & 63.96 \\
\hline Illiterate & 1129 & 36.03 \\
\hline Literate & 636 & 0.13 \\
\hline Socioeconomic status & & 95.8 \\
\hline Lower & 1695 & 0.90 \\
\hline Upper lower & 16 & 1.07 \\
\hline Lower middle & 23 & 0.20 \\
\hline Upper middle & 19 & \\
\hline Upper & 3 & \\
\hline Family Member & 565 & \\
\hline <5 & 1200 & \\
\hline$>5$ & & \\
\hline Status of cases & 1200 & \\
\hline Referred cases & & \\
\hline Directly reported & & \\
\hline Indoor cases & & \\
\hline
\end{tabular}

In the review of previous obstetrics history (14.9\%) cases had previous abortions, (3.17\%) cases had history of previous birth defect, and history of previous stillbirth was seen in $(1.47 \%)$ case as show in Table 2.

Table 2: Review of obstetric history.

\begin{tabular}{|lll|}
\hline Obstetric events & Number & $\%$ \\
\hline Abortions & 264 & 14.9 \\
\hline Previous stillbirth & 26 & 1.47 \\
\hline Previous birth defects & 56 & 3.17 \\
\hline Previous LSCS & 37 & 2.09 \\
\hline
\end{tabular}

Medical cause was traced in $(6.09 \%)$, obstetrical causes were seen in $(31.38 \%)$ placental causes were $(14.10 \%)$ 
while $(47.53 \%)$ cases remains unidentified. Major cause of still birth was Antepartum haemorrhage (8.8\%) and hypertensive disorders of pregnancy $(21.4 \%)$ and infections $(3.0 \%)$ and $(2.54 \%)$ cases had congenital malformation as shown in Table 3.

Table 3: Causes of stillbirth.

\begin{tabular}{|lll|}
\hline Causes & Number & $\%$ \\
\hline Medical causes & 123 & 6.96 \\
\hline Cardiovascular disorder & 3 & 0.16 \\
\hline Neurological disorder & 10 & 0.56 \\
\hline Pulmonary disorder & 2 & 0.11 \\
\hline Endocrine disorder & 10 & 0.56 \\
\hline Haematological & 13 & .73 \\
\hline Infection & 53 & 3.00 \\
\hline Autoimmunological & 1 & 0.056 \\
\hline Previous history of illness & 31 & 1.75 \\
\hline Placental causes & 249 & 14.10 \\
\hline Cord prolapse & 19 & 1.08 \\
\hline Abruptio placenta & 42 & 2.37 \\
\hline Placenta Previa & 115 & 6.50 \\
\hline IUGR & 73 & 4.13 \\
\hline Obstetrical causes & 554 & 31.38 \\
\hline PTLP & 10 & 0.56 \\
\hline PROM & 61 & 3.45 \\
\hline Cholestasis of pregnancy & 5 & 0.28 \\
\hline Multiple pregnancy & 12 & 0.67 \\
\hline ABO Rh incompatibility & 5 & 0.28 \\
\hline Trauma & 2 & 0.11 \\
\hline Previous LSCS & 18 & 1.01 \\
\hline Major congenital malformation & 45 & 2.54 \\
\hline Obstructed labour & 2 & 0.11 \\
\hline Ruptured uterus & 10 & 0.56 \\
\hline Eclampsia and preeclampsia & 379 & 21.4 \\
\hline Chorioamnionitis & 1 & 0.056 \\
\hline GDM & 4 & 0.22 \\
\hline Unexplained & 839 & 47.53 \\
\hline
\end{tabular}

Table 4: Management Review.

\begin{tabular}{|lll|}
\hline $\begin{array}{l}\text { Management } \\
\text { Type of labour }\end{array}$ & Number \\
\hline Induced & 1508 & 85.43 \\
\hline Spontaneous & 96 & 5.4 \\
\hline Mode of delivery & & \\
\hline Vaginal & 1606 & 90.99 \\
\hline LSCS & 156 & 8.8 \\
\hline Instrumental & 3 & 0.16 \\
\hline Birth type & & \\
\hline Macerated & 423 & 23.9 \\
\hline Fresh & 1342 & 76.03 \\
\hline Gender & & \\
\hline Male & 901 & 50.99 \\
\hline Female & 834 & 47.19 \\
\hline ambiguous & 32 & 1.81 \\
\hline
\end{tabular}

Management analysis is shown in table 4 maximum induction of labour has been done $(85.43 \%)$ by various methods as per department standard protocol and $90.99 \%$ had vaginal deliveries, male sex fetus were more stillborn than female foetuses. Fresh stillbirth was seen in $76.03 \%$ cases.

\section{DISCUSSION}

In present study, the incidence for the still birth in study period was $5.5 \%$ that is $55 / 1000$ live birth. It is comparatively higher than the cumulative incidence for India that is $22 / 1000$ live births. ${ }^{1}$ The study site is one of the apices centre for state Haryana and it received most of the referral cases even from other state medical colleges. In present study the number of referral cases were $(\mathrm{N}=1200,67.98 \%)$. On comparison of incidence with other studies, a study done by Neetu Singh et al, it was 40/1000 live birth for a tertiary care centre. ${ }^{6}$ A study done at south India by Divya B et al it was $29.2 \% .^{7}$ The worldwide estimated still birth rate which was collected from 195 countries by Hannah et al4 is 18.4/1000 live birth. Most of the females are primi gravida (45.3\%) which indicates that they are ignorant about the danger sign of pregnancy. These dangers signs are traced in this study that is antepartum haemorrhage, hypertensive disorder of pregnancy, infections and congenital malformations. In present study $95.8 \%$ females belong to low socioeconomic status that is confirmed by a study done at Sweden by Stephansson O. et al also shows the increased stillbirth were seen in low socioeconomic status. $^{8}$

According to Cande V. Ananth hypertensive disorders are major group in contribution of stillbirth 4.8 to $7.8 / 1000$ live birth among primi to multi gravid females. ${ }^{9}$ A retrospective analysis done for antepartum haemorrhage and its perinatal outcome done at norther Nigerian teaching hospital indicates the stillbirth rate alone with APH is $42.8 \%$ in the study period that is quite high. ${ }^{10}$ Infection is associated with stillbirth in present study was $3.0 \%$ and infection is also a preventable cause for still birth which need timely identification and intervention to reduce the total incidence of stillbirth. A study done by Goldenberg RL et al has shown in his study that infection is also one of the major sources of stillbirth in developing countries compared to developed countries. ${ }^{11}$ Major congenital malformation also contributes $2.45 \%$ cases to stillbirth and there is also history of previous malformation in $3.17 \%$ which cannot be ignored as contributor in stillbirth. A study done by P. Shayam shows the congenital malformation is $1.45 \%$ of total stillbirth. ${ }^{12}$ Unexplained stillbirth is one of the major domain of this study which constitute $47.3 \%$ cases. A systematic review was done at University of Queensland, Australia by HE Reinebrant et al they classified 50 countries into High income countries (HIC), Middle Income countries (MIC), and Low Middle Income countries (LIC) and found unexplained stillbirth $32.1 \%$, $43.7 \%$, and $41.0 \%$ respectively. India was categorized in 
Low income country. ${ }^{13}$ WHO has launched a programme in year 2014 ENAP i.e. "EVERY NEWBORN an action plan to end preventable deaths". It came with the vision of "A world in which there are no preventable deaths of new borns or stillbirths, where every pregnancy is wanted, every birth celebrated, and women, babies and children survive, thrive and reach their full potential". It is having goal of "By 2035, all countries will reach the target of 10 or less stillbirths per 1000 total births and continue to close equity gaps". ${ }^{14}$

\section{CONCLUSION}

Stillbirth is a hidden component of new born health status which is often neglected when we talk about perinatal mortality and infant mortality.

Most of the cases in the present study belong to low socioeconomic status, illiterate, and were of rural background which indicates outreach facilities are still in need to improve the quality care and awareness of danger signs of pregnancy.

There are some preventable causes like infection, proper monitoring of hypertensive disorder cases, obstructed labour, which could be avoided by proper protocols in hospital.

Lethal congenital malformation is also continuing beyond 20 weeks and patients had to take burden of the pregnancy as well psychological impact of carrying a fetus which is having no fate so every facility mandate awareness programme among family of pregnant females that a malformation scan is mandatory before 20 weeks so that MTP could be offered.

Unidentified stillbirth needs exploration of some identifiable rare causes so that the rate of stillbirth could be reduced and ENAP goal could be achieved. To conclude every birth should be counted upon and to be investigated to prevent the preventable death and a mandatory regular registry system should be made for the state as well as the country.

\section{ACKNOWLEDGMENTS}

Author would like to acknowledge to all junior residents who have well maintained the files to accomplish this retrospective analysis and all those authors whose study included for comparison analysis.

Funding: No funding sources Conflict of interest: None declared

Ethical approval: Not required

\section{REFERENCES}

1. WHO. International statistical classification of diseases and related health problems: tenth revision, volume 2: Instruction manual. $10^{\text {th }}$ revision: 2010 Edition.

2. American College of Obstetricians and Gynecologists. ACOG Practice Bulletin No. 102: management of stillbirth. Obstet Gynecol. 2009;113(3):748-61.

3. Guideline GT. 55-Late Intrauterine Fetal Death and Stillbirth. London: Royal College of Obstetricians and Gynaecologists. 2010.

4. Blencowe H, Cousens S, Jassir FB, Say L, Chou D, Mathers $\mathrm{C}$, et al; National, regional, and worldwide estimates of stillbirth rates in 2015, with trends from 2000: a systematic analysis: Lancet Global Health. 2016;4(2):e98-108.

5. Lawn JE, Blencowe H, Pattinson R, Cousens S, Kumar R, Ibiebele I, et al, Lancet's Stillbirths Series Steering Committee. Stillbirths: Where? When? Why? How to make the data count? The Lancet. 2011;377(9775):1448-63.

6. Singh N, Pandey K, Gupta N, Arya AK, Pratap C, Naik R. A A retrospective study oInt J Reprod Contracept Obstet Gynecol. 2013;2(2):141-146

7. Balu D, Nayak A, Swarup A. A study of intrauterine fetal death in a tertiary care hospital. Int J Reprod Contracept Obstet Gynecol. 2015;4:2028-31

8. Stephansson O, Dickman PW, Johansson AL, Cnattingius S; The influence of socioeconomic status on stillbirth risk in Sweden. Int $\mathrm{J}$ Epidemiol. 2001;30(6):1296-301

9. Ananth CV, Basso O. Impact of pregnancy-induced hypertension on stillbirth and neonatal mortality in first and higher order births: a population-based study. Epidemiol (Cambridge, Mass.). 2010;21(1):118.

10. Takai IU, Sayyadi BM, Galadanci HS, Antepartum Hemorrhage: A Retrospective Analysis from a Northern Nigerian Teaching Hospital; Int J Appl Basic Med Res. 2017;7(2):112-6.

11. Goldenberg RL, Thompson C. The infectious origins of stillbirth. Am J Obstet Gynecol. 2003;189(3):861-73.

12. Shyam P., Analysis of risk factors of stillbirth: a hospital-based study in a tertiary care centre. Int $\mathbf{J}$ Reprod Contracept Obstet Gynecol. 2016;5(2):525-529

13. Reinebrant HE, Leisher SH, Coory M, Henry S, Wojcieszek AM, Gardener G et al. Making stillbirths visible: a systematic review of globally reported causes of stillbirth. BJOG: Int J Obstet Gynaecol. 2018;125(2):212-24.

14. WHO: Every Newborn: an action plan to end preventable deaths. Available at http://www.who.int/maternal_child_adolescent/docume nts/every-newborn-action-plan/en/

Cite this article as: Gautam S, Rani V, Dalal M., Retrospective analysis of stillbirth at a tertiary care hospital. Int J Reprod Contracept Obstet Gynecol 2018;7:4012-5. 